\title{
The Use of Nuclear Reactions and SIMS for Quantitative Depth Profiling of Hydrogen in Amorphous Silicon
}

\author{
David D. Allred \\ allred@byu.edu \\ G. J. Clark \\ C. W. White \\ B. R. Appleton \\ C. W. Magee
}

See next page for additional authors

Follow this and additional works at: https://scholarsarchive.byu.edu/facpub

Part of the Astrophysics and Astronomy Commons, and the Physics Commons

\section{Original Publication Citation}

G.J. Clark, C.W. White, David D. Allred, B.R. Appleton, C.W. Magee, and D.E. Carlson, "The use of nuclear reactions and SIMS for quantitative depth profiling of hydrogen in amorphous silicon," Applied Physics Letters 31, 582585 (1977).

\section{BYU ScholarsArchive Citation}

Allred, David D.; Clark, G. J.; White, C. W.; Appleton, B. R.; Magee, C. W.; and Carlson, D. E., "The Use of Nuclear Reactions and SIMS for Quantitative Depth Profiling of Hydrogen in Amorphous Silicon" (1977). Faculty Publications. 1213.

https://scholarsarchive.byu.edu/facpub/1213 
Authors

David D. Allred, G. J. Clark, C. W. White, B. R. Appleton, C. W. Magee, and D. E. Carlson 
In conclusion, the plasmon energy losses in the Auger spectra of an $\mathrm{Al}-\mathrm{Zn}-\mathrm{Mg}$ alloy provide information concerning the chemical environment of individual elements in the alloy, from which a better understanding of the grain-boundary segregation and precipitation can be achieved. This important aspect is expected to be equal ly well applicable to other alloy systems.

The authors acknowledge the financial support of the Office of Naval Research (Contract No. 00014-74-C0277) and are grateful to P.A. Clarkin for his constant encouragement.

${ }^{1}$ L. A. Harris, J. Appl. Phys. 39, 1419 (1968).

${ }^{2}$ T. W. Haas, J. T. Grant, and G. J. Dooley III, J. Appl. Phys. $43,1853(1972)$
${ }^{3}$ P.w. Palmberg, Anal. Chem, 45, 549-A (1973).

${ }^{4}$ P. M. Hall, J. M. Morabito, and D. K. Conley, Surf. Sci. 62, 1 (1977).

${ }^{5}$ M. P. Seah, J. Phys. F 3, 1538 (1973).

${ }^{6}$ R. F. Cook and S. L. Cundy, Philos. Mag. 20, 665 (1969).

${ }^{7}$ P. Doig and J.W. Edington, Philos. Mag. 28, 961 (1973)

${ }^{8}$ P. Doig, J. W. Edington, and G. Hibbert, Philos. Mag. 28, 971 (1973).

9W. M. Mularie and T.W. Rusch, Surf. Sci. 19, $469(1970)$.

${ }^{10}$ J. J. Chang and D. C. Langreth, Phys, Rev. B 8, 4638 (1973).

${ }^{11}$ P. W. Palmberg, G. E. Riach, P.E. Weber, and N. C. MacDonald, Handbook of Auger Electron Spectroscopy

(Physical Electronics Industries, Edina, Minn. 1976).

${ }^{12}$ P. N. T. Unrvin and P. B. Nicholson, Acta Metall. 17, 1379 (1969).

${ }^{13}$ J. M. Chen, T.S. Sun, R. K. Viswanadham, and J.A.S. Green, Metall. Trans. A (to be published).

${ }^{14} \mathrm{H}$. Y. Hunsicker, Aluminum, edited by K. R. VanHorn (American Society for Metals, Metals Park, Ohio, 1967), Vol. I.

\title{
The use of nuclear reactions and SIMS for quantitative depth profiling of hydrogen in amorphous silicona)
}

\author{
G. J. Clark, C. W. White, D. D. Allred, and B. R. Appleton \\ Solid State Division, Oak Ridge National Laboratory, Oak Ridge, Tennessee 37830 \\ C. W. Magee and D. E. Carlson
}

RCA Laboratories, Princeton, New Jersey 08540

(Received 20 July 1977; accepted for publication 16 August 1977)

\begin{abstract}
Depth profiles for hydrogen in amorphous silicon have been determined by the use of resonant nuclear reactions $\left[{ }^{1} \mathrm{H}\left({ }^{15} \mathrm{~N}, a \gamma\right){ }^{12} \mathrm{C}\right.$ and $\left.{ }^{1} \mathrm{H}\left({ }^{19} \mathrm{~F}, \alpha \gamma\right){ }^{16} \mathrm{O}\right]$ and by secondary ion mass spectroscopy (SIMS). Independent calibration procedures were used for the two techniques. Measurements were made on the same amorphous silicon film to provide a direct comparison of the two hydrogen analysis techniques. The hydrogen concentration in the bulk of the film was determined to be about 9 at.\% $H$. The SIMS results agree with the resonant nuclear reaction results to within $10 \%$, which demonstrates that quantitative hydrogen depth profiles can be obtained by SIMS analysis for materials such as amorphous silicon.
\end{abstract}

PACS numbers: $61.70 . \mathrm{Wp}, 82.80 . \mathrm{Ms}, 82.80 . \mathrm{Jp}$

The importance of understanding the role hydrogen plays in energy-related materials has recently been stressed. ${ }^{1}$ In many cases, quantitative information is required on the depth distribution of hydrogen in a material as well as its total hydrogen content. Many of the conventional techniques of elemental analysis such as ESCA, Auger, XRF, neutron or charged-particle activation, Rutherford backscattering, and electron microprobe are not directly applicable to hydrogen determination. Two methods that have the potential of providing quantitative depth information for the total hydrogen content of materials are (1) nuclear reactions and (2) secondary ion mass spectrometry (SIMS).

In this paper we describe the application of these two techniques to the quantitative determination of the hy drygen profile in an amorphous silicon film. This is a

\footnotetext{
a) Research sponsored by the Energy Research and Development administration under contract with Union Carbide Corporation.
}

technological problem of considerable current interest. ${ }^{2,3}$ It is thought ${ }^{4}$ that hydrogen which has been incorporated into amorphous silicon films prepared by glow discharge in a silane atmosphere plays an important role in allowing such films to be substitutionally doped.

As an analysis technique, it is well known that resonant nuclear reactions can provide quantitative nondestructive depth profile information but the sensitivity is limited due to the magnitude of the nuclear-reaction cross section (typically $10^{-25} \mathrm{~cm}^{2}$ ). SIMS on the other hand has the potential to detect all the elements in the periodic table with high sensitivity, but quantitative information has been very difficult to obtain because secondary ion yields are a complicated function of the sputtered species and the chemical environment. SIMS should be able to provide sensitive depth profile infor mation about hydrogen in materials by detecting hydrogen ions sputtered from ion-bombarded surfaces, but the application of this technique to hydrogen measure- 


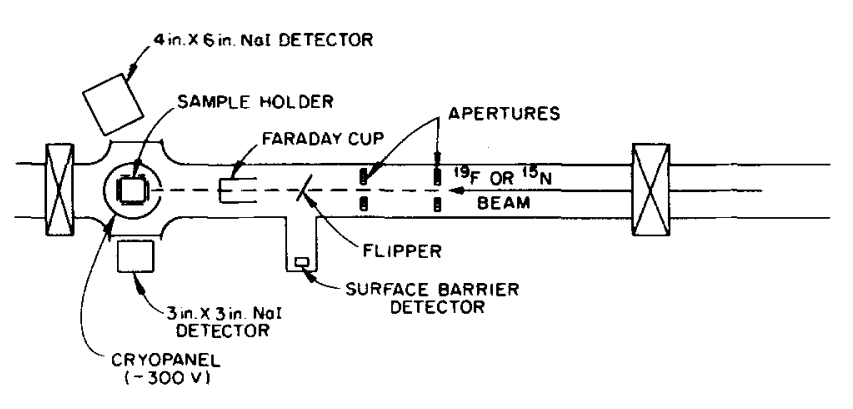

Experimental Apparatus for Hydrogen Depth Profiling.

FIG. 1. Schematic representation of the experimental arrangement used for the nuclear-reaction measurements described in the text.

ments has been hampered by the fact that most experimental apparatus have been operated in the $10^{-6}-10^{-7}$ Torr range. ${ }^{5}$ At these pressures, deposition of hydrogen-containing molecules on the surface represents a constant source of hydrogen to the sample during analysis. We have overcome this problem by performing SIMS measurements in a vacuum with a base pressure of $10^{-10}$ Torr using a finely focused $\mathrm{Ar}^{+}$ion beam for sputtering. In amorphous silicon, we find that quantitative depth profile information by SIMS is pos sible if proper attention is paid to calibration procedures. We demonstrate the quantitative aspects of SIMS analysis by a direct comparison of the hydrogen profile determined by SIMS in an amorphous silicon film with the hydrogen profile as determined in the same by the use of two resonant nuclear reactions.

The amorphous silicon film $(a-\mathrm{Si})$ used in this work was prepared ${ }^{3}$ by dc cathodic deposition in silane onto a stainless-steel substrate. The gas pressure was 2 Torr, the current density $1 \mathrm{~mA} \mathrm{~cm}^{-2}$, and the substrate temperature $350{ }^{\circ} \mathrm{C}$.

For hydrogen depth profiling by resonant nuclear reactions, strong narrow isolated resonances in the cross section of the ${ }^{1} \mathrm{H}\left({ }^{15} \mathrm{~N}, \alpha \gamma\right){ }^{12} \mathrm{C}$ and ${ }^{1} \mathrm{H}\left({ }^{19} \mathrm{~F}, \alpha \gamma\right){ }^{16} \mathrm{O}$ reactions have independently been used. Only a brief description of the use of these techniques will be given here as they have been described elsewhere. ${ }^{7-9}$ To use these reactions for depth profiling, the incident beam energy is varied to step the depth at which the resonance occurs through the sample. At a given energy, the yield of $\gamma$ rays is proportional to the hydrogen concentration in a thin layer $\Delta \chi_{R}$ at a depth of $\chi_{R}$. The depth at which the resonance occurs is determined by the stopping power, ${ }^{10}$ $d E / d \chi$, while the thickness being analyzed is determined by the width of the resonance and the energy straggling of the beam. Using the $6.38-\mathrm{MeV}$ resonance in the ${ }^{1} \mathrm{H}\left({ }^{15} \mathrm{~N}, \alpha \gamma\right){ }^{12} \mathrm{C}$ reaction, a depth resolution of $60 \AA$ at the surface and $200 \AA$ at a depth of $4000 \AA$ is possible in silicon. The depth resolution of the $16.44-\mathrm{MeV}$ ${ }^{1} \mathrm{H}\left({ }^{19} \mathrm{~F}, \alpha \gamma\right){ }^{16} \mathrm{O}$ resonance varies from $\sim 250 \AA$ at the sur face to $\sim 300 \AA$ at a $4000-\AA$ depth in silicon. Measuring the $\gamma$-ray yield as a function of beam energy then gives a direct indication of the hydrogen concentration as a function of depth in the sample.

At energies different from the resonance energies the cross section for the ${ }^{1} \mathrm{H}\left({ }^{15} \mathrm{~N}, \alpha \gamma\right){ }^{12} \mathrm{C}$ and the ${ }^{1} \mathrm{H}\left({ }^{19} \mathrm{~F}, \alpha \gamma\right){ }^{16} \mathrm{O}$ reactions are not negligible and corrections must be made for this during data analysis. The procedure for this correction is described elsewhere. ${ }^{g}$

The experimental apparatus for the nuclear-reaction measurements is shown in Fig. 1. The ${ }^{19} \mathrm{~F}^{+3}$ or ${ }^{15} \mathrm{~N}^{+2}$ beams, provided by the Oak Ridge National Laboratory Tandem Van de Graaff accelerator, were collimated to a beam spot of $\sim 0.4 \mathrm{~cm}$ in diameter, striking the target at normal incidence. Beam currents of 30 and $10 \mathrm{nA}$ were used for the ${ }^{19} \mathrm{~F}$ and ${ }^{15} \mathrm{~N}$ beams, respectively. The beam currents were monitored by (1) particles backscattered from a tantalum flipper rotating in the beam, the flipper being calibrated with a Faraday cup and (2) current integrated directly off the target, the target holder being surrounded by a $\mathbf{L N}_{2}$ shroud held at -300

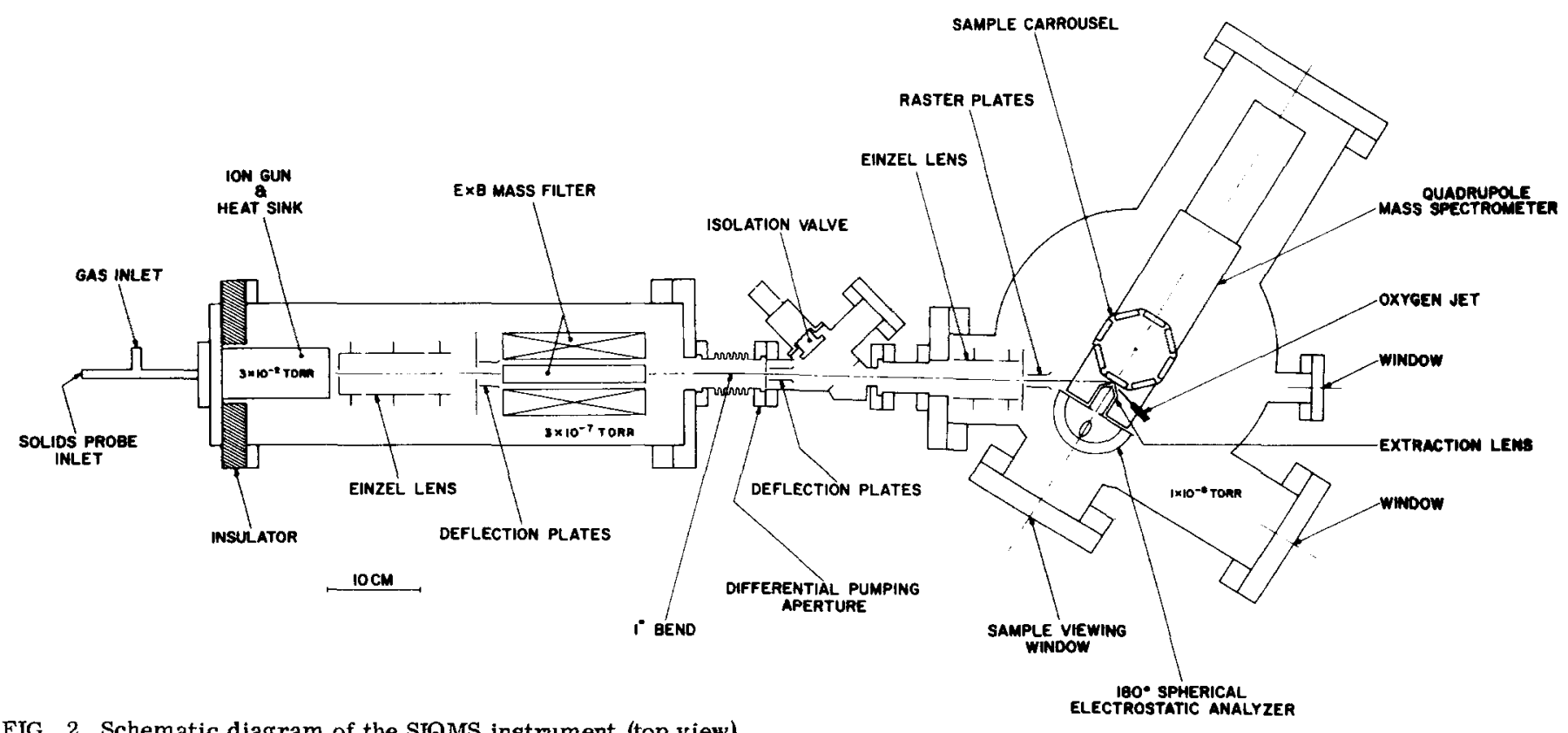

FIG. 2. Schematic diagram of the SIQMS instrument (top view). 
$\mathrm{V}$ to suppress electrons from the target. The vacuum in the target chamber was $\sim 10^{-7}$ Torr. The $\gamma$ rays were detected in both a $3 \times 3-\mathrm{in}$. NaI detector placed approximately $2 \mathrm{~cm}$ from the target and at $90^{\circ}$ to the beam direction and a $6 \times 4$-in. NaI detector placed approximately $10 \mathrm{~cm}$ from the target and at $135^{\circ}$ to the beam direction.

The hydrogen content of samples studied was determined in absolute terms by comparison of $\gamma$-ray yields with similar yields obtained from calibration samples. The calibration samples used in this work were poly ethelyne $\left[\left(\mathrm{CH}_{2}\right)_{n}\right]$, Lexan $\left[\left(\mathrm{C}_{16} \mathrm{H}_{14} \mathrm{O}_{3}\right)_{n}\right]$, and a $\mathrm{H}^{+}(10$ $\left.\mathrm{keV}, 4 \times 10^{16} \mathrm{~cm}^{-2}\right)$ implanted silicon wafer. The calibration constants for the ${ }^{15} \mathrm{~N}$ and ${ }^{19} \mathrm{~F}$ reactions obtained from these different standards had standard deviations of $13 \%$, for both beams.

In the SIMS analysis, ${ }^{11-13}$ the samples were bombarded with a $5-\mathrm{keV}$ beam of ${ }^{40} \mathrm{Ar}^{+}$primary ions, causing the outermost layers to be sputtered off. The majority of particles left as neutral particles, but a small fraction left as positive or negative ions. These ions were focused into a quadrapole mass spectrometer for separation according to their mass/charge ratio. Since the primary ion beam continuously eroded the sample by sputtering, monitoring one or several masses as a function of time yielded an in-depth concentration profile. The mass spectrometer was capable of identifying all elements in the periodic table complete with isotopic information, thus enabling SIMS to detect hydrogen.

Figure 2 shows the layout of the SIQMS (secondary ion quadrapole mass spectrometer) apparatus ${ }^{11-13}$ which was used for the SIMS analysis. The primary ion beam column was located to the left of the sample chamber. The primary ion beam was formed in an arc discharge ion source, mass analyzed using an $\mathbf{E} \times \mathbf{B}$ velocity filter, and focused by two electrostatic lenses onto the sample. The angle of incidence was $60^{\circ}$ to the surface normal, and the spot size and current density were $70 \mu \mathrm{m}$ in diameter and $25 \mathrm{~mA} / \mathrm{cm}^{2}$, respectively. The beam was rastered in a pattern approximately $1 \mathrm{~mm}^{2}$ in order to sputter a flat-bottom crater which was needed for good depth resolution. Electronic signal gating was used to reduce crater edge effects. Under these conditions,

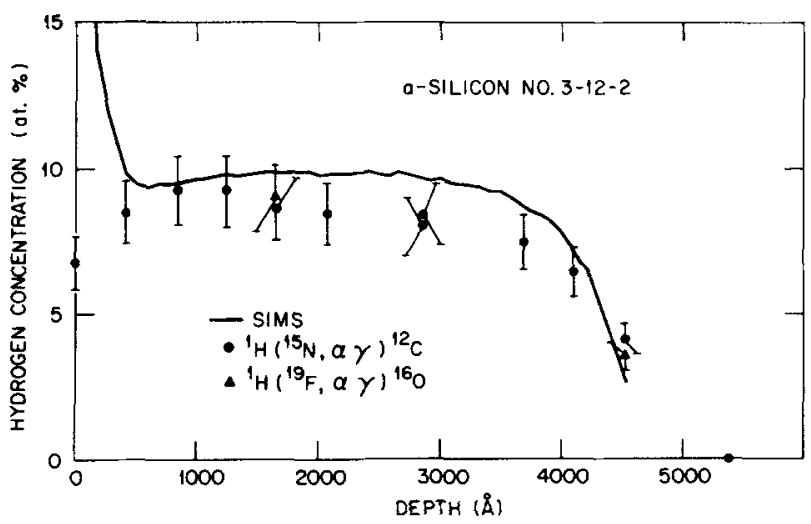

FIG. 3. Hydrogen concentration versus depth into film for glow-discharge-prepared amorphous-Si sample. Profiles determined by SIQMS and the two nuclear reactions, $\left.{ }^{1} \mathrm{H}\left({ }^{15} \mathrm{~N}, \alpha \gamma\right)\right)^{12} \mathrm{C}$ and $\left.{ }^{1} \mathrm{H}\left({ }^{19} \mathrm{~F}, \alpha \gamma\right)\right)^{16} \mathrm{O}$. the sputtering rate was typically $10 \mathrm{~A} / \mathrm{sec}$. A quadrapole mass spectrometer with an energy filter was used to monitor the secondary ions sputtered from the surface region. Hydrogen and water vapor in the target chamber were maintained at partial pressures in the $10^{-10}$-Torr range by a titanium sublimation pump and large-area liquid-nitrogen cold wall.

The large range in elemental sensitivities and the matrix or chemical effects encountered in SIMS required the use of a standard sample of hydrogen in silicon to quantify the hydrogen profile in the amorphous silicon. The standard chosen was a piece of single-crystal silicon accurately implanted with $50-\mathrm{keV}$ protons to a dose of $7.5 \times 10^{15}$ atoms $/ \mathrm{cm}^{2}$. The peak hydrogen concentration for this sample was $5 \times 10^{20}$ atoms $/ \mathrm{cm}^{3}$ or 1 at. $\%$ and the profile was followed down from that peak three orders of magnitude in concentration. Using this as a standard for hydrogen sensitivity in silicon, a concentration scale could be assigned to the depth profile of hydrogen in the amorphous silicon sample.

The hydrogen profile of the $a-\mathrm{Si}$ sample as determined with both the ${ }^{1} \mathrm{H}\left({ }^{15} \mathrm{~N}, \alpha \gamma\right){ }^{12} \mathrm{C}$ and the ${ }^{1} \mathrm{H}\left({ }^{19} \mathrm{~F}, \alpha \gamma\right){ }^{16} \mathrm{O}$ reactions is shown in Fig. 3. The errors shown include both statistical and calibration errors. Also show shown in Fig. 3 is the negative secondary ion profile from the same $a-\mathrm{Si}$ film. The large yield of $\mathrm{H}^{-}$from the surface in the SIMS resulted from surface contamination containing hydrogen. This was completely removed by sputtering $\sim 300$ A deep into the sample.

The film thickness shown in Fig. 3 for the nuclear reaction data is $4500 \pm 300 \AA$. This was determined from stopping power data ${ }^{10}$ for ${ }^{15} \mathrm{~N}$ and ${ }^{19} \mathrm{~F}$ ions assuming a film density of $2.0 \mathrm{~g} \mathrm{~cm}^{-3}$. The film density was determined by weighing. Independent ${ }^{4} \mathrm{He}$ backscattering energy loss measurements gave a thickness of $5000 \pm 300$ $\AA$ (again assuming $\rho=2 \mathrm{~g} \mathrm{~cm}^{-3}$ ). The film thickness shown in Fig. 3 for the SIMS data is $4200 \pm 100 \AA$. This was determined by the Talysurf technique. ${ }^{14}$

As shown in Fig. 3, the hydrogen concentration in the bulk of the film as determined by the three techniques was $\sim 4.3 \times 10^{21} / \mathrm{cm}^{3}$ or 9.0 at. $\%$ H. The absolute magnitude and the profile of hydrogen determined by the two resonant nuclear reactions was in excellent agreement with the SIMS results. The fact that excellent agreement was obtained showed that in the SIMS measurements there was no significant difference in the hydrogen-containing molecular fragments sputtered from the amorphous silicon film as compared to the ion-implanted calibration sample. Also the chemical environments of the two samples were similar enough such that there was no significant difference attributable to chemical matrix effects or differences in sputtered ion neutralization probabilities. In some materials there is evidence ${ }^{3}$ for hydrogen mobility under beam conditions but repeated measurements on $a$-Si showed no evidence for hydrogen mobility in this material at room temperature. These results show that if proper attention is paid to calibration procedures and to the vacuum environment, then SIMS can be used for quantitative hydrogen profile measurements in materials such as amorphous silicon. 
The hydrogen concentration that we have measured by the combined techniques of resonant nuclear reactions and SIMS are in broad agreement with hydrogen concentrations measured by others ${ }^{4}$ for $a-S i$ films prepared under similar conditions. Infrared measurements on $a-\mathrm{Si}$ material prepared in the manner described above have also given hydrogen concentration results similar to our results, indicating that the majority of the hydrogen contained in the film is bonded, presumably compensating dangling Si bonds. It should be noted that in $a$-Si solar cell development studies information on the hydrogen profile is a useful diagnostic. Cell failure can frequently be related to interface problems caused by hydrogen build up. Moreover, diffusion of hydrogen at temperatures $\geq 350^{\circ} \mathrm{C}$ can create dangling bonds that degrade cell efficiency.

${ }^{1}$ F. L. Vook, H. K. Birnbaum, T. H. Blewitt, W. L. Brown, J.W. Corbett, J.H. Crawford, A.N. Goland, G. L.

Kulcinski, M.T. Robinson, D. N. Seidman, and F.W. Young, Rev. Mod. Phys. 47 (1975).
${ }^{2}$ H. R. Leuchtag, Phys. Today 30 (No. 1), 17 (1977).

${ }^{3}$ D. E. Carlson, IEEE Trans. Electron Devices ED-24, 449 (1977).

${ }^{4}$ M. H. Brodsky, M. A. Frisch, J. F. Ziegler, and W. A. Lanford, Appl. Phys. Lett. 30, 561 (1977).

${ }^{5} \mathrm{James} \mathrm{R}$. Hinthorne and C. A. Anderson, Amer. Mineral. 60,143 (1975).

${ }^{6}$ J.I. Pankove and D. E. Carlson, Appl. Phys. Lett. 29, 620 (1976).

'D.A. Leich and T.A. Tombrello, Nucl. Instrum. Methods 108, 67 (1973)

${ }^{8}$ W. A. Lanford, H. P. Tratvetter, J. F. Ziegler, and J. Keller, Appl. Phys. Lett. 28, 566 (1976)

${ }^{9}$ G. J. Clark, C.W. White, D.D. Allred, B. R. Appleton, F. B. Koch, and C.W. Magee, Nuclear Instrum. Methods (to be published).

${ }^{10}$ L. C. Northcliffe and R. F. Schilling, Nucl. Data Tables A 7, 233 (1970).

${ }^{11}$ C.W. Magee, W. L. Harrington, and R. E. Honig, 3rd Annual Conference of the F.A.C.S.S., Philadelphia, 1976

(unpublished).

${ }^{12} \mathrm{C}$. W. Magee, W. L. Harrington, and R. E. Honig, Rev. Sci. Instrum, (to be published).

${ }^{13} \mathrm{C}$. W. Magee and C.P. Wu. Nucl. Instrum. Methods (to be published).

${ }^{14} \mathrm{D} . J$. Whitehouse, Characterization of Solid Surfaces, edited by Kane and Larabee (Plenum, New York, 1974), p. 53.

\title{
Changes in x-ray diffraction patterns of polyvinylidene fluoride due to corona charging
}

\author{
D. K. Das Gupta and K. Doughty \\ School of Electronic Engineering Science, University College of North Wales, Dean Street, Bangor, \\ Gwynedd LL57 1UT, Great Britain \\ (Received 9 June 1977; accepted for publication 31 August 1977)
}

\begin{abstract}
The changes in the $\mathrm{x}$-ray diffraction patterns of 16- and $25-\mu \mathrm{m}$-thick polyvinylidene fluoride films, caused by $6-\mathrm{kV}$ corona charging at room temperature, are presented. The diffraction peaks corresponding to (100) and (020) $\alpha$-crystalline forms tend to be considerably reduced while the (110) $\beta$-form peak changes in shape and position.
\end{abstract}

PACS numbers: $77.90 .+k, 81.60 . J w, 61.40 . \mathrm{Km}, 73.40 . \mathrm{Bf}$

Polyvinylidene fluoride $\left(\mathrm{PVF}_{2}\right)$ is a semicrystalline polymer which may exist at least in two stable crystalline forms, ${ }^{1}$ namely, a planar zigzag polar form $(\beta$ form or Form 1$)^{2}$ and a $T-G-T-\bar{G}$ nonpolar form ( $\alpha$ form or Form 2$)^{3}$ where $T, G$, and $\bar{G}$ denote the trans and the two types of gauche forms, respectively. Oshiki and Fukada ${ }^{4}$ show that a significant reduction of the $\alpha$ form takes place on stretching and subsequently subjecting the $\mathbf{P V F}_{2}$ films, originally containing both $\alpha$ and $\beta$ forms, to high dc fields over extended periods of time at elevated temperatures (i. e. , poling). The infrared and Raman spectroscopic studies of Latour ${ }^{5}$ also support such observations on poling of $\mathrm{PVF}_{2}$ films. Tamura et al ${ }^{6}$ detected changes in the polarized infrared spectrum which indicated an orientation of $\beta$-form crystallites on poling and this is supported by the changes in the $\mathrm{x}$-ray diffraction pole figure of $\operatorname{Kepler}^{7}$ for poled and unpoled samples. Southgate ${ }^{8}$ reports a significant reduction of the infrared absorption peaks at 762 and 975 $\mathrm{cm}^{-1}$, which have been ascribed to the $\alpha$ form, ${ }^{9}$ after poling using a corona charging source at voltages of up to $\pm 6 \mathrm{kV}$ at room temperature.

An attempt has been made in the present study to observe changes in molecular conformation due to corona charging of $16-$ and $25-\mu \mathrm{m}$-thick films of $\mathrm{PVF}_{2}$ by $x$-ray diffraction techniques. The films were supplied by the Kureha Chemical Industry Co. Ltd. , of Japan. Test samples $\sim 3 \mathrm{~cm}^{2}$ in area were cleaned with acetone and diffraction patterns were recorded for Bragg angles (i. e., $2 \theta$ ) between $16^{\circ}$ and $23^{\circ}$ using the step scanning technique and $\mathrm{Ni}$-filtered $\mathrm{Cu}-K$ radiations. The samples were then corona charged at room temperature to a surface potential $\pm 6 \mathrm{kV}$ using a similar technique to that of Southgate ${ }^{8}$ and diffraction patterns redetermined. The results are shown in Figs. 1 and 2. Table I provides a summary of the peak positions observed (i.e., $2 \theta$ values) in the present work and the corresponding crystallographic data of $\mathrm{PVF}_{2}$ (without corona charging) due to Hasegawa et al. ${ }^{10}$ Although no internal standard 